\title{
PRÁCTICAS DE CULTURA ORGANIZACIONAL A DISTANCIA DESDE UNA PERSPECTIVA DE RESPONSABILIDAD SOCIAL EMPRESARIAL
}

\section{DISTANCE ORGANIZATIONAL CULTURE PRACTICES FROM A CORPORATE SOCIAL RESPONSIBILITY PERSPECTIVE}

DOI: www.doi.org/10.54198/innova08.02

\author{
(D) Brianda Guadalupe González Vega ${ }^{1}$ \\ (iD) Alejandra Morales Vargas ${ }^{2}$ \\ (iD) Yarene Itzel Marín Jimeno ${ }^{3}$ \\ (iD) Miriam Liliana Barajas Ruíz ${ }^{4}$
}

Cómo citar esté artículo: González Vega, B. G., Morales Vargas, A., Marín Jimeno, Y. I. \& Barajas Ruiz, M. L. (2021). Prácticas de cultura organizacional a distancia desde una perspectiva de responsabilidad social empresarial, Revista Innova ITFIP, 8 (1), $12-18$

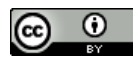

\section{Resumen}

Recibido: enero de 2021. Aprobado: mayo de 2021

La situación ocasionada por la COVID-19 ha propiciado el desarrollo tecnológico, así como la transformación, adaptación e innovación en los procesos organizacionales a distancia, permitiendo que las y los trabajadores realicen sus labores vía remota. El presente proyecto analiza prácticas de Cultura Organizacional a distancia desde una perspectiva de Responsabilidad Social Empresarial (RSE). Se utilizó la metodología estudio de caso mediante la aplicación de un cuestionario a 21 estudiantes de la carrera Técnico Superior Universitario, Área Capital Humano, de la Universidad Tecnológica de Querétaro (UTEQ), México. Los resultados previos muestran un listado de rasgos y prácticas para mantener y propiciar una Cultura Organizacional a distancia en la que se practique la RSE.

Palabras Clave: Responsabilidad Social Empresaria. (RSE) Prácticas de cultura organizacional.

\footnotetext{
${ }^{1}$ Maestra en Docencia Universidad Tecnológica de Querétaro. (UTEQ) Cuerpo Académico "Innovación Tecnológica para el Desarrollo de Negocios" (UTEQ). México. Correo electrónico: brianda.gonzalez@ uteq.edu.mx Orcid: https://orcid.org/0000-00034636-921X

${ }^{2}$ Universidad Tecnológica de Querétaro. (UTEQ) Técnico Superior Universitario en Administración área Capital Humano Colaborador del Cuerpo Académico "Innovación Tecnológica para el Desarrollo de Negocios" (UTEQ), México. Correo electrónico: alemorales.v@outlook.es ORCID: https://orcid.org/0000-0001-9476-325X

${ }^{3}$ Maestra en Administración con especialidad en Finanzas. Profesor de Tiempo Completo en Universidad Tecnológica de Querétaro. (UTEQ) Coordinadora del Cuerpo Académico "Innovación Tecnológica para el Desarrollo de Negocios" (UTEQ), México. Correo electrónico: yarene.marin@uteq.edu.mx, ORCID: https://orcid.org/0000-0003-1360-1000

${ }^{4}$ Doctorado en administración por la Universidad de Celaya-Guanajuato. mbarajas@ uteq.edu.mx. ORCID: https://orcid.org/ 0000-0001-8973-6003
} 


\begin{abstract}
:
The situation caused by COVID-19 has led to technological development as well as transformation, adaptation and innovation in remote organizational processes, allowing workers to perform their work remotely. This project analyzes remote Organizational Culture practices from a Corporate Social Responsibility (CSR) perspective. The case study methodology was used by applying a questionnaire to 21 students of che Higher Technical University career, Human Capital Area, of the Technological University of Querétaro (UTEQ), Mexico. The previous results show a list of tarots and practices to maintain and promote a remote Organizational Culture in which CSR is practiced.
\end{abstract}

Keywords: Corpórea Social Responsibility. (CSR) Organizational culture practices.

\title{
Introducción
}

El presente documento tiene como finalidad abordar las prácticas de cultura organizacional a distancia desde una perspectiva de Responsabilidad Social Empresarial. Debido a las circunstancias actuales provocadas por la pandemia ${ }^{1}$ de la COVID- $19^{2}$ es importante analizar los cambios en los procesos organizativos y educativos, los cuales han incentivado una modificación cultural e innovación empresarial, estas, en conjunto con las nuevas tecnologías. De igual modo, es importante mostrar el desarrollo de estrategias de Responsabilidad Social Empresarial (en adelante RSE) que impacten de forma positiva en aspectos culturales, sociales y medioambientales para las empresas, que ayuden a alcanzar objetivos comunes y a una gestión eficaz y eficiente del negocio. (Díaz et al., 2018).

En ese sentido, tomando como punto de partida la relevancia e importancia que ha adquirido la RSE, es necesario promoverla y seguir los parámetros que permiten situar a estas empresas socialmente responsables, así como el desarrollo de las mismas.

De manera tal, se vuelve relevante visibilizar las propuestas del estudiantado universitario el cual se encuentra en el mundo laboral, considerando que tales estudiantes representan el capital humano en formación dentro de las organizaciones.

\section{Materiales y métodos}

El presente proyecto de investigación tiene como referente un diseño metodológico abierto, en el que se complementa la revisión teórica, así como la aplicación de instrumentos que den cuenta de la problemática abordada. La metodología desarrollada es estudio de caso.

\footnotetext{
${ }^{1}$ OMS, (2020), Se llama pandemia a la propagación mundial de una nueva enfermedad

2 OMS, (2020), La COVID-19 es la enfermedad infecciosa causada por el coronavirus que se ha descubierto más recientemente. Tanto este nuevo virus como la enfermedad que provoca eran desconocidos antes de que estallara el brote en Wuhan (China) en diciembre de 2019. Actualmente la COVID-19 es una pandemia que afecta a muchos países de todo el mundo
} 
Dentro de un estudio de caso la información se puede adquirir de forma cualitativa o cuantitativa, en documentos, entrevistas, observación directa y objetos físicos, permitiendo comprobar y comparar una o más hipótesis, así como confirmar teorías existentes, además las investigaciones pueden ser descriptivas o exploratorias, dependiendo lo que se pretenda conseguir.

"El estudio de casos se caracteriza porque presenta especial atención a cuestiones que específicamente pueden ser conocidas a través de casos. El caso puede ser simple o complejo y puede ser un niño, una clase, o un colegio" (Buendía, 1998, p. 257).

\section{Marco Teórico:}

La cultura organizacional es considerada como el conjunto de conductas, valores, creencias, hábitos y comportamientos que distinguen a una organización de las demás, la cual se crea mediante un proceso de socialización con un grupo de individuos que mantienen relaciones formales e informales y que comparten intereses en común (Dominguez, 2009). Lo anterior, respondiendo al cumplimiento de los objetivos organizacionales, los cuales permiten que las y los trabajadores tengan un sentido de pertenencia dentro de la organización, provocando así efectos positivos (o no), además, de generar mayor compromiso, lealtad, mejorando la calidad y productividad dentro de la empresa.

Por tanto, la cultura organizacional refleja una amplia contextualización de la empresa, misma que se puede relacionar con las prácticas de Responsabilidad Social Empresarial que pueda tener la organización.

Sobre la perspectiva anteriormente planteada, nos encontramos con Vallaeys (2007) quien refiere a la Responsabilidad Social Empresarial como aquella exigencia ética y una estrategia racional de desarrollo para la inteligencia organizacional, en donde se pide que las organizaciones respondan por sus acciones y consecuencias en el mundo y responder a los diversos grupos interesados o afectados.

Desde la conceptualización que marca Vallaeys (2007), se entiende que las organizaciones deben posicionarse bajo dos perspectivas, la primera de ellas tiene como base el responder por la "excelencia", la "democracia" y la "ecología", donde se enfatiza las pretensiones (calidad de sus productos y servicios, rendición de cuentas, reportes, evaluación, así como los estándares, normas y auditoría externa) y los impactos (cuidado, prevención, respeto, análisis de impactos, amortización con el entorno) también, deben responder a buscar el mejoramiento continuo, dividiéndose en sus partes interesadas (diálogo y negociación, participación, solución de conflictos, Transparencia, confiabilidad y satisfacción de necesidades), y sus partes afectadas (anticipación de riesgos, política sostenible a largo plazo, visión ética global).

Por su parte, Cajiga (2020), en el Centro Mexicano para la Filantropía (CMEFI) reconoce que: La responsabilidad Social Empresarial es el compromiso consciente y congruente de cumplir integralmente con la finalidad de la empresa, tanto en lo interno como en lo externo, considerando 
REVIST A INNOVA ITFIP, 8 (1). 12-18. JUN. 2021

las expectativas económicas, sociales y ambientales de todos sus participantes, demostrando respeto por la gente, los valores éticos, la comunidad y el medio ambiente, contribuyendo así a la construcción del bien común. (p. 4)

Por tanto, la cultura organizacional, así como la RSE se encuentran ligadas a las prácticas que la organización realiza.

"La cultura comprende valores compartidos, hábitos, usos y costumbres, códigos de conducta, políticas de trabajo, tradiciones y objetivos que se transmiten de una generación a otra" (Chiavenato, 2009, p. 120). La cultura se puede definir como el conjunto de normas, de estilo, valores y formas de pensar que caracterizan el comportamiento, posicionamiento del personal en todos los niveles de la empresa, las actuaciones de la dirección, el estilo de la dirección, la forma de asignar recursos, la forma de organizar esa corporación, así como la imagen de la empresa. De esta forma la cultura empresarial se recoge y se manifiesta en símbolos, rituales, tabúes, mitos y otras manifestaciones donde los valores están ordenados por una preferencia jerárquica (Leyva Granados, 2008, p. 30).

\section{Resultados y Discusión}

Los resultados del apartado Datos generales encontramos que el 33\% de los estudiantes corresponde al género masculino y el $67 \%$ al femenino. En cuanto a la edad, el promedio es de 25 años.

Respecto a la actividad que se realiza, el estudiantado pudo elegir más de una opción, dando como resultado que el 100\% realiza estadías, mientras que 52\% trabajan en empresa, así mismo, el 23\% realizan proyecto de investigación y el $4 \%$ todas las anteriores.

Siguiendo con el apartado de datos generales, a la pregunta “¿Durante el periodo de contingencia (Ocasionado por la COVID 19) realizaste Home Office, ya sea en tu trabajo o estadía?", el 76\% realizó home office mientras que el $24 \%$ no. Además, el $52 \%$ contesta que no existen momentos para trabajar en conjunto o esclarecer dudas y el $48 \%$ restante afirma que sí.

Así mismo, las herramientas que utilizan para realizar Home Office el 100\% utilizan internet para desempeñar sus actividades laborales o de estadía, lo que permite afirmar que toda la población encuestada hace uso de las nuevas tecnologías. 57\% utilizan computadora, $38 \%$ hacen uso de softwares, $9 \%$ emplean celular y posteriormente el 5\% asume que todas las anteriores.

Las respuestas en torno al proceso de cambio ocurrido a causa de la presente pandemia, los resultados muestran, en general, que la mayoría sufre tensión en mayor o menor medida ocasionada por la pandemia de la Covid-19, ya que el $38 \%$ se sienten estresados o abrumados, así mismo un $28 \%$ presionados, $24 \%$ expresan otras respuestas, $14 \%$ se sitúan nostálgicos y tristes, un $9 \%$ de los estudiantes se sienten optimistas y finalmente otro $9 \%$ expresan que experimentan sentirse mal.

En cuanto al segundo apartado de la encuesta, la pregunta ¿Conoces cuál es la misión, visión y valores (Filosofía organizacional) de la empresa? Los resultados indican que la mayoría de las y 
los estudiantes (76\%) conoce la filosofía organizacional impartida dentro de la empresa donde labora, mientras que el $19 \%$ no la conoce, y finalmente, el 5\% restante no cuenta con filosofía organizacional. Está es de gran importancia, ya que si los colaboradores la conocen y se sienten identificados con ella será más fácil que se cumplan las políticas, objetivos y metas planteadas.

Continuando con la estructura del instrumento, el 90\% de los estudiantes refiere que dentro de la organización donde labora se promueve el respeto a las y los empleados, tan sólo el 10\% restante revela lo contrario. Por lo tanto, esto quiere decir que la mayoría forma parte de una organización donde se promueve una cultura de respeto, en la cual valoran al personal. Esto concuerda con lo que dice (Domínguez, 2009).

En el apartado de Responsabilidad Social Empresarial, donde se encuentran las siguientes respuestas en torno a la pregunta “¿Qué entiendes por Responsabilidad Social Empresarial?” Las y los estudiantes tienen diversas concepciones del significado: es la responsabilidad del empleado (18\%), sustentabilidad dentro de la organización (18\%), lo que la empresa devuelve a la sociedad (18\%), el compromiso/compromiso con la sociedad (9\%), lo que se hace dentro de la empresa, (4.5\%), no sé el concepto (4.5\%), prácticas voluntarias que promuevan equilibrio social, económico y medioambiental $(4.5 \%)$, respeto y buena convivencia $(4.5 \%)$, mejorar al personal $(4.5 \%)$, reducir costos $(4.5 \%)$, acciones y funciones de los empleados $(4.5 \%)$ conciencia (4.5\%).

Mientras que la pregunta ¿Consideras que la empresa en la te encuentras actualmente promueve la Responsabilidad Social Empresarial? El $48 \%$ asume que dentro de la organización donde labora la Responsabilidad Social Empresarial se promueve mientras el 52\% restante lo niega.

Los tipos de programas que se implementan dentro de la organización, la mayoría (33\%) alude que no se implementan programas que apoyen el equilibrio ambiental dentro de la organización donde laboran, siendo algo preocupante ya que, $14 \%$ expresa que se realizan campañas ambientales, otro $10 \%$ nos dice que es a través de selección de desechos, dinámicas así mismo un 10\% opina no conocer los programas que se implementan, $5 \%$ no dice que es mediante reciclaje y uso de energías limpias y los tipos de programas, el 5\% del estudiantado indica que los programas son mediante dinámicas grupales, así como convivencias festivas, $2 \%$ alude no saber, otro $2 \%$ expresa que no se implementa ningún programa y otro $2 \%$ responde que es mediante la reducción de la jornada.

De igual manera para continuar con el análisis, respecto a la pregunta ¿Dentro de la organización donde laboras se generan oportunidades basadas en la inclusión, equidad y desarrollo profesional? muestra que el $71 \%$ de los y las estudiantes indica que dentro de la organización donde labora existen y se crean oportunidades de inclusión, equidad y desarrollo profesional, finalmente $29 \%$ lo negó. En cuanto al ¿Cómo? La mayoría (95\%) del estudiantado no respondió, $19 \%$ dice que no existen, mientras un $14 \%$ comenta que las oportunidades generan son mediante planes de carrera, seguido por $9 \%$ que indica es motivando al personal, $5 \%$ comenta que hay inclusión, respeto y creación de actividades, así mismo $5 \%$ expresa que la empresa es nueva. 
Díaz, M., Palma, E., Leiva, F., Varón O., Alarcón, A. y Sandoval, L. (2018) “Avances de investigación en ciencias económicas, administrativas y contables" Editorial: Instituto Tolimense de Formación Técnica Profesional-ITFIP 187 pp. ISBN: 978-958-59986-4-3. Recuperado de: https://n9.cl/40xmf

Fraile, E. (2016). La gestión de la responsabilidad social corporativa. El caso Unilever España. Obtenido. https://www.tdx.cat/bitstream/handle/10803/384844/ebf1de1.pdf;jsessionid=98AF156EC0E88963 35F09FA8D8A13A2D?sequence=1

García, M., \& Sanmartín, R. (1973). La encuesta.

Leyva, \&. A. (2008). Desarrollo de una cultura empresarial contra el paradigma de las agencias publicitarias.

Muñoz, T. (2003). Etapas del Proceso Investigador: INSTRUMENTACIÓN.

Robbins, S. (2013). Comportamiento organizacional (Decimoquinta ed.). México: Person educación de México, S.A. de C.V.

Sparkes, A., \& Devís J. (2007). viref.udea.edu.co/. Recuperado de http://viref.udea.edu.co/contenido/publicaciones/memorias_expo/cuerpo_ciudad/investigacion_nar rativa.pdf

Sampieri, R. (1997). Metodología de la investigación. Colombia: MCGRAW-HILL

Sarmiento, S. (2011). Responsabilidad Social Empresarial: gestión estratégica para la supervivencia de las empresas. Dimens. Empres, 6-15.

Bateman, S. A. (2005). Administración: Un nuevo panorama competitivo. (Segunda edición ed.).

Vallaeys, F. (2007). La responsabilidad social universitaria: un nuevo modelo universitario contra la mercantilización Revista Iberoamericana de Educación Superior. Revista Iberoamericana de Educación Superior, $12 . \quad$ Obtenido de Disponible en: https://www.redalyc.org/articulo.oa?id=2991/299129977006

Villalón, R., Hernández, C. A., \& Ochoa Jiménez, S. (27 de noviembre de 2016). La cultura organizacional enfocada a la responsabilidad social empresarial y la relación con el recurso humano: una propuesta de estudio. Obtenido de http://www.cyta.com.ar/ta1503/v15n3a3.htm 